\title{
KOLABORASI TRIPLE HELIX DALAM PEMBANGUNAN WISATA BAHARI DI INDONESIA
}

\author{
Amni Zarkasyi Rahman dan Hardi Warsono
}

Program Studi Administrasi Publik, Fakultas Ilmu Sosial dan Ilmu Politik, Universitas

Diponegoro

amni.rahman@live.undip.ac.id

\begin{abstract}
Abstrak
Triple helix merupakan konsep kolaborasi yang mendukung dalam pembangunan wisata bahari melalui hubungan dua arah antara government, business, dan academia. Peran government memiliki porsi yang lebih besar untuk mempersiapkan payung regulasi dalam perencanaan sektoral yang akan dilaksanakan oleh business dan academia. Penelitian ini digunakan metode kualitatif deskriptif bertujuan untuk mendeskripsikan secara jelas masalah penelitian tentang potensi kolaborasi triple helix serta implikasi bagi wisata bahari di Indonesia. Government berperan dalam menyediakan kerangka regulasi (RPJM dan Perda); business memberikan bantuan finansial dalam program CSR; sedangkan academia menyusun master plan pemberdayaan sekaligus menjadi fasilitator dalam lingkup kegiatan pengabdian kepada masyarakat.
\end{abstract}

Kata Kunci: triple helix, government, wisata,

\begin{abstract}
Triple helix is a collaboration concept that supports the development of marine tourism through a two-way relationship between government, business, and academia. The role of the government is bigger than other, such as: formulating sectoral regulation that will be implemented by business and academia. This research used descriptive qualitative method, to describe triple helix collaboration and implications for marine tourism in Indonesia. Government's role is to providing the regulatory framework (RPJM and Local Regulation); the business provides financial supportwith CSR programs; while academia develops a master plan for empowerment as well as being a facilitator with community service activities.

Keywords:triple helix, government, tourism
\end{abstract}




\section{PENDAHULUAN}

Indonesia merupakan salah satu negara destinasi wisata dunia dengan berbagai potensi melimpah, mulai dari adventure tourism, ecotourism hingga coastal\&marine tourism atau yang lebih dikenal dengan sebutan wisata bahari. Meskipun bentuk coastal\&marine tourism berbeda, namun sangat erat hubungannya dan kadang menjadi suatu kesatuan (Hall, 2001). Perlu diketahui, bahwa wisata bahari merupakan bentuk pariwisata tertua yang memiliki segmen pasar yang luas, sehingga orang selalu meluangkan waktu untuk sekedar berwisata di pantai (Orams, 2002). Saat ini, lebih dari 30.000 kapal pesiar melakukan perjalanan dengan tujuan lebih dari 2000 pantai yang berbeda di seluruh dunia, termasuk destinasi pantai-pantai di Indonesia (Honey \& Krantz, 2007).

Salah satu destinasi wisata bahari popular tersebut adalah Pantai Sanur Bali dengan jumlah wisatawan macanegara mencapai 4,1 juta di Tahun 2015

(http://www.disparda.baliprov.go.id).

Adapun daya tarik utama destinasi ini adalahsunrise spot, pantai pasir putih, seawalker, snorkeling, dan scuba diving. Selain itu, terdapat dukungan penuh infrastruktur penunjang seperti hotel, restaurant, souvenir shop, shopping centre, spa, ATM, money changer, dan infastruktur lainnya. Hal inilah yang mampu menunjang tinggiinya tingkat kunjungan wisatawan mancanegara disamping branding Bali yang sudah mendunia.
Selain itu, terdapat juga kawasan Raja Ampat di Papua dengan jumlah wisatawan mencapai 18.000 di tahun 2018

(http://travel.kompas.com/read/2015/10/ 08/141600827/Kadispar.Raja.Ampat.Op timistis.Raih.18.000. Wisman).

Destinasi ini memiliki beberapa daya Tarik utama, seperti diving, snorkeling, dll. Akan tetapi, jumalh kunjungan ini lebih rendah dari jumlah kunjungan wisata di Phi Phi Island Thailand yang mampu mencapai 30.000 di tahun 2015 (https://en.wikipedia.org/wiki/Phi_Phi_I slands), bahkan masih kalah jauh dibandingkan kunjungan wisatawan ke Sipadan, Malaysia yang mampu mencapai 774.276 kunjungan di tahun yang sama (http://www.sabahtourism.com/sites/def ault/files/visitor-jan-nov-2015.pdf).

Meskupun demikian, grafik jumlah wisatwan asing yang berkunjung ke Indonesia dalam kurun waktu 20122016 menunjukkan trend postitif sebagai berikut :

Gambar 1 Perkembangan Jumlah

Kunjungan Wisman Ke Indonesia dan

Devisa Tahun 2012 - 2016

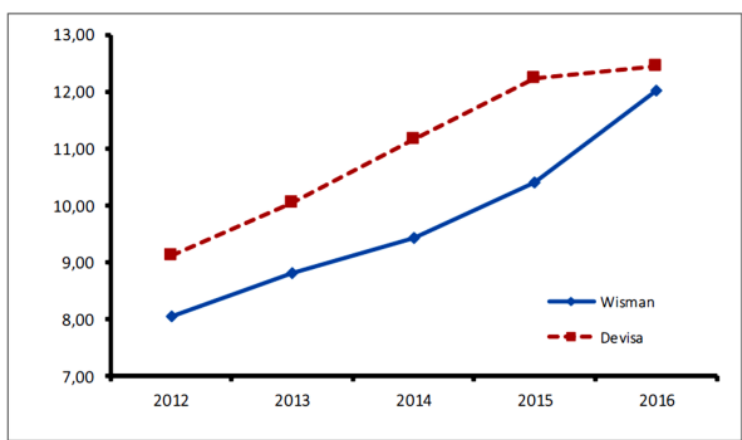

Sumber : Statistik Profil Wisatawan Mancanegara, 2016

Berdasarkan gambar tersebut, diketahui bahwa terdapat peningkatan 
$15,54 \%$ jumlah wisatawan mancanegara yang berkunjung ke Indonesia dibandingkan tahun sebelumnya. Peningkatan ini mampu memberikan devisa sebesar 12,44 milyar USD, meningkan $1,75 \%$ dari tahun sebelumnya. Rata-rata wisatawan itu melakukan kunjungan pada destinasi wisata bahari yang sangat melimpah di Indonesia.

Sebetulnya, selain kawasan wisata bahari yang telah menjadi primadona tersebut, masih banyak kawasan yang penuh potensi namun belum tereksplorasi dengan baik, sebagai contohnya adalah kawasan pantai teluk penyu Cilacap Selatan serta Pantai Karang Bolong Nusakambangan. Kedua pantai ini masih dalam kondisi sederhana, namun memiliki potensi yang cukup besar, mulai dari kondisi pantai, komunitas nelayan, serta pemandangan bawah laut. Akan tetapi, potensi wisata bahari ini belum mampu disentuh oleh investor sehingga masih menjadi golongan pantai-pantai "biasa" di Indonesia.

Oleh karena itu, diperlukan rencana strategis dalam rangka membangun potensi wisata bahari yang "biasa" di Indonesia, melalui peran serta aktiv para stakeholders. Rencana strategis yang relevan digunakan adalah kolaborasi stakeholders antara government, business, dan academia yang lebih dikenal dengan triple helix (Etzkowitz \& Leydesdorff, 2000).

\section{METODE}

Kolaborasi Triple Helixdalam peningkatan wisata bahari harus dapat dipahami secara menyeluruh melalui pemikiran ilmiah sebagai masalah secara signifikan. Oleh karena itu, penelitian ini digunakan metode kualitatif deskriptif bertujuan untuk mendeskripsikan secara jelas masalah penelitiantentang potensi kolaborasi triple helix serta implikasi bagi wisata bahari di Indonesia (Creswell \& Creswell, 2017). Lebih lanjut, potensi kolaborasi akan lebih dilihat melalui peran dari masing-masing pihak, yaitu government, business, dan academia. Selanjutnya, data dikumpulkan melalui studi literatur(Sugiyono, 2013)seperti jurnal ilmiah yang relevan (Webster \& Watson, 2002), media online, serta portal berita resmi.

\section{HASIL DAN PEMBAHASAN}

\section{Government sebagai Pembuat Kebijakan}

Perkembangan sektor pariwisata tidak lepas dari peran pemerintah sebagai decision maker berbagai kebijakan terkait. Hal ini juga tercantum dalam rencana pembangunan sectoral dalam lingkup RPJM. Akan tetap, sejauh mana keterlibatan pemerintah dengan tumbuhnya sektor pariwisata masih belum dapat diukur, terlebih dengan adanya korelasi langsung antara pengembangan SDM bidang pariwisata dengan pesatnya perkembangan destinasi wisata (Baum \& Szivas, 2008).

Salah satu alasan yang mendasari intervensi pemerintah dalam pembangunan sector pariwisata adalah sector ini mampu memberikan dampak postif secara bersamaan pada perkembangan ekonomi dan social. 
Terlebih dengan adanya kegiatan prekrutan, pelatihan, pendidikan dan pendampingan dalam mengelola daerah wisata (Ireland, 2005). Kondisi ideal ini masih belum terlihat di Indonesia, terlebih peran pemerintah yang secara langsung berhubungan dengan penyiapan SDM bidang pariwisata justru kurang mendapat perhatian (peran dari SMK/ Sekolah Tinggi pariwisata). Padahal pendidikan vokasi bidang pariwisata memiliki peran vital dalam menciptakan SDM yang unggul sehingga mampu memberikan pengaruh pada perkembangan positif pariwisata (Riley, Ladkin, \& Szivas, 2002)

Sementara itu, arah kebijakan pariwisata Indonesia tahun 2015-2019 yang terdiri dari : 1) Pemasaran pariwisata; 2) Pembangunan destinasi pariwisata; 3) Pembangunan industri pariwisata; dan 4) Pembangunan kelembagaan pariwisata berusaha untuk mecapai sasaran pertumbuhan sebagai berikut :

Tabel 1 Sasaran Pertumbuhan Priwisata 2015-2019

\begin{tabular}{|l|l|c|c|}
\hline No & \multicolumn{1}{|c|}{$\begin{array}{c}\text { Uraian } \\
\text { Sasaran }\end{array}$} & $\begin{array}{c}\text { Baseline } \\
\mathbf{2 0 1 4}\end{array}$ & $\mathbf{2 0 1 9}$ \\
\hline 1 & $\begin{array}{l}\text { Kontribusi } \\
\text { terhadap PDB } \\
\text { nasional }\end{array}$ & $4,2 \%$ & $8 \%$ \\
\hline 2 & $\begin{array}{l}\text { Wisatawan } \\
\text { Mancanegara } \\
\text { (orang) }\end{array}$ & 9 juta & 20 juta \\
\hline 3 & $\begin{array}{l}\text { Wisatawan } \\
\text { Nusantara } \\
\text { (kunjungan) }\end{array}$ & 250 juta & 275 juta \\
\hline 4 & $\begin{array}{l}\text { Devisa (triliun } \\
\text { rupiah) }\end{array}$ & 120 & 240 \\
\hline
\end{tabular}

Sumber : BAPPENAS, 2014
Sasaran ini harus menjadi motivasi dalam usaha pembangunan sektor pariwisata, meskipun wisata bahari menyumbang 35\% dari wisata alam. Salah satu kebijakan yang dibuat pemerintah adalah pengembangan 10 destinasi pariwisata prioritas, dengan 6 diantaranya merupakan wisata bahari, yaitu : 1) Tanjung Kelayang; 2) Kepulauan Seribu; 3) Mandalika; 4) Labuan Bajo; 5) Wakatobi; dan 6) Morotai.

Pemerintah saat ini sangat concern dalam melakukan pendekatan pengembangan destinasi wisata berbasis produk, seperti atraksi, aksesibilitas, dan amenitas. Cakupan dari atraksi adalah daya tarik yang bias berbasis utama pada kekayaan alam, budaya, maupun buatan/ artificial, seperti event atau yang sering disebut sebagai minat khusus (special interest); kemudian aksesibiltas meliputi : dukungan sistem transportasi yang meliputi : rute atau jalur transportasi, fasilitas terminal, bandara, pelabuhan dan moda transportasi yang lain; serta amenitas yang meliputi : fasilitas penunjang dan pendukung wisata yang meliputi: akomodasi, rumah makan (food and beverage), retail, toko cinderamata, fasilitas penukaran uang, biro perjalanan, pusat informasi wisata, dan fasilitas kenyamanan lainnya (Sunaryo, 2013).

Government sebagai pembuat kebijakan tentu saja tidak dapat membangun desinasi wisata tersebut tanpa kolaborasi dengan berbagai stakeholders terkait. Terlebih dengan jumlah anggaran yang terbatas, segala proses pembangunan tidak dapat 
dilaksanakan dalam waktu yang relatif singkat. Diperlukan kolaborasi antara business dan academia untuk menyusun masterplan pembangunan wisata bahari yang sustainable.

\section{Kolaborasi \\ Mutualisme}

\section{Pembangunan Wisata Bahari}

Untuk membangun kolaborasi, kita perlu melakukan identifikasi stakeholders yang akan berperan aktif. Stakeholders ini akan lebih tersinergi apabila terdapat kejelasan dari institutions. Institutions disini merupakan bagian dari public stakeholders (Odendaal, 2003) yang secara luas mampu mempengaruhi pelaksanaan pembangunan wisata bahari. Selain itu, terdapat juga private stakeholders(Cano, Hernandez, \& Ros, 2014), dan academias institution yang lebih dikenal dengan universitas (Lombardi, Giordano, Farouh, \& Yousef, 2012). Kolaborasi ini nantinya akan membentuk hubungan mutulisme antara state(government), academia, dan industry (business)(Etzkowitz \& Leydesdorff, 2000) dalam kerangka Triple Helix seperti pada gambar berikut:

Gambar 2 Model Laissez-Faire dari Hubungan Triple Helix

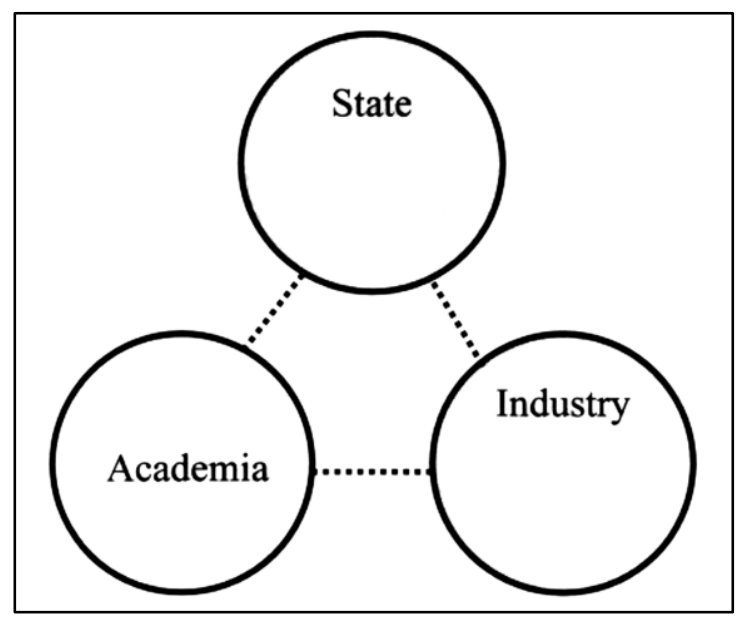

Sumber : (Etzkowitz \& Leydesdorff, 2000)

Implementasi kolaborasi ini dapat terlihat dari peran masing-masing stakeholder sesuai dengan batasan masing-masing. Government dapat membuat kebijakan tentang pembangunan wisata bahari, serta kebijakan tentang sumbangan pihak ketiga dalam pembangunan dalam bentuk peraturan daerah. Melalui kebijakan tersebut, business mendapatkan legalisasi peran dalam bentuk program Corporate Social Responsibility (CSR). CSR yang dilakukan oleh business tidak hanya terpaku pada program charity, namun juga empowerment untuk menjaga aspek sustainability (Hopkins, 2017). Oleh karena keterbatasan dari business dalam menyediakan fasilitator yang akan memberdayakan masyarakat, diperlukan peran dari academia untuk menjadi pendamping pelaksanaan pemberdayaan tersebut.

Pelaksanaan pendampingan yang dilakukan oleh academia di Indonesia terlihat dari implementasi salah satu Tri Dharma Perguruan Tinggi, yaitu Pengabdian kepada Masyarakat. Akan tetapi, peran tersebut belum maksimal dilakukan karena belum banyak kegiatan pengabdian kepada masyarakat yang merupakan bentuk kolaborasi tersebut. Salah satu upaya pemerintah dalam "mengkondisikan" adanya peran itu adalah melalui panduan penelitian dan pengabdian kepada masyarakat yang dikeluarkan Kementerian Riset, Teknologi, dan Perguruan Tinggi setiap tahunnya. Salah satu skema penagdian kepada masyarakat kompetitif nasional 
yang mendukung kolaborasi ini adalah Program Kemitraan Wilayah (PKW).

PKW dilatarbelakangi bebagai permasalahan yang merupakan masalah kewilayahan yang terjadi di masyarakat dalam satu desa atau satu kelurahan, yaitu : 1) ketidakmapanan sebagian besar masyarakat terhadap pembangunan kehidupan pribadi, keluarga, da masyarakat dalam era globalisasi; 2) IPTEK perguruan tinggi belum secara sengaja ditujukan bagi kesejahteraan masyarakat desa atau kelurahan; 3) potensi masyarakat maupun sumberdaya alam lingkungannya beum termanfaatkn dengan baik dan arif; serta 4) penatakelolaan fisik kewilayahan yang belum proporsional dan professional (Dimyati, 2018).

\section{PENUTUP}

\section{Simpulan}

Triple helix merupakan bentuk kolaborasi yang diperlukan dalam membangun wisata bahari di Indonesia, yang terdiri dari government, business, dan academia. Government berperan dalam menyediakan kerangka regulasi (RPJM dan Perda); business memberikan bantuan finansial dalam program CSR; sedangkan academia menyusun master plan pemberdayaan sekaligus menjadi fasilitator dalam lingkup kegiatan pengabdian kepada masyarakat.

\section{Saran}

1. Diperlukan regulasi pusat yang dapat "mewajibkan" kolaborasi triple helix dalam pembangunan sector wistaa bahari
2. Diperlukan penelitian lebih lanjut tentang peran community sebagai subjek dan objek pemberdayaan masyarakat yang menjadi focus pembangunan SDM bidang pariwisata.

\section{DAFTAR PUSTAKA}

Baum, T., \& Szivas, E. (2008). HRD in tourism: A role for government? Tourism Management, 29(4), 783-794.

Cano, J., Hernandez, R., \& Ros, S. (2014). Distributed framework for electronic democracy in smart cities. Computer, 47(10), 65-71.

Creswell, J. W., \& Creswell, J. D. (2017). Research design: Qualitative, quantitative, and mixed methods approaches: Sage publications.

Dimyati, M. (2018). Panduan Penelitian dan Pengabdian Kepada Masyarakat Edisi XII Tahun 2018 (XII ed.). Jakarta: Kementerian Riset, Teknologi, dan Pendidikan Tinggi.

Etzkowitz, H., \& Leydesdorff, L. (2000). The dynamics of innovation: from National Systems and "Mode 2" to a Triple Helix of universityindustry-government relations. Research Policy, 29(2), 109$123 . \quad$ doi: https://doi.org/10.1016/S00487333(99)00055-4

Hall, C. M. (2001). Trends in ocean and coastal tourism: the end of the last frontier? Ocean \& coastal management, 44(9-10), 601-618.

Honey, M., \& Krantz, D. (2007). Global trends in coastal tourism: Center 
on Ecotourism and Sustainable Development.

Hopkins, M. (2017). CSR and sustainability CSR and Sustainability (pp. 59-87): Routledge.

Ireland, F. (2005). A human resource development strategy for Irish tourism: competing through people. Failte Ireland, Dublin.

Lombardi, P., Giordano, S., Farouh, H., \& Yousef, W. (2012). Modelling the smart city performance. Innovation: The European Journal of Social Science Research, 25(2), 137-149.

Odendaal, N. (2003). Information and communication technology and local governance: understanding the difference between cities in developed and emerging economies. Computers, Environment and Urban Systems, 27(6), 585-607.

Orams, M. (2002). Marine tourism: development, impacts and management: Routledge.

Riley, M., Ladkin, A., \& Szivas, E. (2002). Tourism employment: Analysis and planning (Vol. 6): Channel View Publications.

Sugiyono, M. P. K. (2013). Kualitatif, dan Kombinasi (Mixed Methods). Bandung: Alfabeta.

Sunaryo, B. (2013). Kebijakan Pengembangan Destinasi Pariwisata. Gava Media, Yogyakarta.

Webster, J., \& Watson, R. T. (2002). Analyzing the past to prepare for the future: Writing a literature review. MIS quarterly, xiii-xxiii. http://www.disparda.baliprov.go.id, , diakses pada tanggal 10 Oktober 2018 jam 21.40

http://travel.kompas.com/read/2015/10/ 08/141600827/Kadispar.Raja.A mpat.Optimistis.Raih.18.000.Wi $\underline{\text { sman, diakses pada tanggal } 10}$ Oktober 2018 jam 21.42

https://en.wikipedia.org/wiki/Phi_Phi_I slands, diakses pada tanggal 10 Oktober 2018 jam 21.44

http://www.sabahtourism.com/sites/defa ult/files/visitor-jan-nov2015.pdf, diakses pada tanggal 10 Oktober 2018 jam 21.45 